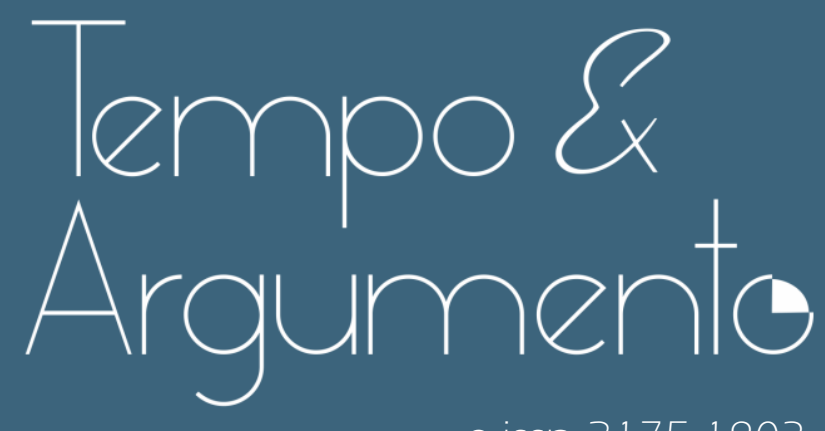

e-issn 2175-1803

Memórias coletivas em disputa: o embate entre memórias e estratégias identitárias em entrevistas jornalísticas

- Agnes Francine de Carvalho Mariano

Doutora em Ciências da Comunicação pela Universidade de São Paulo (USP).

Professora na Universidade Federal de Ouro Preto (UFOP).

Mariana, MG - BRASIL

lattes.cnpq.br/6422229750567834

agnesmariano.ssa@gmail.com

(D) orcid.org/0000-0003-1981-8278

Para citar este texto:

MARIANO, Agnes. Memórias coletivas em disputa: o embate entre memórias e estratégias identitárias em entrevistas jornalísticas [Debate]. Revista Tempo e

Argumento, Florianópolis, v. 12, n. 29, e0301. jan/abr. 2020.

doi) dx.doi.org/10.5965/2175180312292020e030 1

Recebido: 06/08/2019

Aprovado: 24/09/2020 
Partimos, aqui, da premissa de que, nas entrevistas, o diálogo entre entrevistador e entrevistado envolve as experiências e representações vividas e construídas por ambos sobre o passado, e que tais representações dialogam fortemente com suas identidades. Portanto, as entrevistas também são diálogos ou embates entre memórias guiadas por estratégias identitárias. Como área interdisciplinar, a Comunicação sempre buscou aportes em outros campos. Entretanto, a recorrência às Ciências Sociais e à Filosofia sempre predominou e somente nos últimos anos temos visto maior aproximação, por exemplo, com a História. Recentemente, conceitos como memória e temporalidade passaram a ser mais usuais.

Segundo Barbosa, o principal legado para pensar o jornalismo dentro da Comunicação deriva da Sociologia, em torno da qual se têm formulado as Teorias do Jornalismo. Mas, para a autora, essa abordagem deixa um lapso explicativo acerca dos porquês nos processos comunicacionais, que podem ser ricamente explorados com a ajuda da Teoria da História (BARBOSA, 2005 apud MATHEUS, 2011, p. 27).

Na tentativa de observar o que se dá na relação vivida em uma entrevista jornalística, quais são seus motivos, seus riscos e suas virtudes, percorremos o conteúdo das interações e o quão "verídico" ele pode ser, dialogando com conceitos dos estudos sobre a memória: a) as diferentes manifestações da memória; b) a indissociabilidade entre memória e identidade; e c) as ideias de memória coletiva, memórias abertas e fechadas, esquecimentos e silenciamentos. Ao longo deste texto nos reportaremos a uma entrevista veiculada em 2018, durante a campanha eleitoral à Presidência do Brasil, com o então candidato à Vice-Presidência, Antônio Hamilton Mourão. Longe de ser uma escolha aleatória, acreditamos que o trecho sintetiza aspectos importantes para compreender uma vigorosa disputa de memórias que se acentua no Brasil contemporâneo e que tem repercutido fortemente nas pautas dos veículos de comunicação e nas redes sociais, já anunciando ambições de influenciar políticas públicas.

Não é novidade o fato de que há cerca de 6 anos o Brasil ingressou em um novo momento político, marcado pelo acirramento das tensões. Jornadas de Junho de 2013, campanha eleitoral à Presidência de 2014, impeachment da 
presidenta Dilma Rousseff, governo Temer, campanha eleitoral à Presidência de 2018 e o atual governo Bolsonaro parecem ser etapas de um processo complexo que não dá sinais de desfecho. Partiremos de um exemplo nesse contexto para discutir o tema das memórias coletivas, sua relação com as identidades e os desafios no convívio entre essas diferentes memórias.

Durante a campanha eleitoral à Presidência de 2018, os candidatos à Presidência e à Vice-Presidência foram entrevistados em diversos veículos. Descrevemos, aqui, uma dessas entrevistas. Na verdade, um trecho, muito expressivo, de diálogo entre a jornalista Miriam Leitão e o candidato Hamilton Mourão. A sequência de perguntas e respostas durou 1 minuto e 37 segundos e ocorreu no programa Sabatina GloboNews, exibido pela TV a cabo GloboNews em 7 de setembro de 2018, com duração aproximada de 1 hora (GLOBONEWS, 2018). O então candidato Mourão estava sendo entrevistado por 7 jornalistas quando, após 27 minutos de entrevista, ocorreu o seguinte trecho de diálogo exclusivo com Miriam Leitão:

Antônio Hamilton Mourão (AHM) - [...] Tivemos o governo Geisel, extremamente estatizante, mas também tivemos o Castelo Branco, que tinha Roberto Campos e Otávio Gouveia de Bulhões, que foi o passo inicial, né?

Miriam Leitão (ML) - Foi um período muito curto de pensamento mais liberal.

AHM - Foi pouco, é...

$M L$ - O senhor acha que eles erraram?

AHM - Acho que Geisel errou. Acho. Acho. É minha visão.

ML - Só Geisel? Médici não? Ninguém?

AHM - Médici foi diferente, foi um governo diferente. Agora, o Geisel foi o homem que realmente...

ML - O senhor acha que foi melhor? Médici foi um melhor governo do que Geisel?

AHM - Foi. Na minha visão, sim.

ML - Mas não foi o período mais duro da ditadura, da repressão? AHM - É... Miriam, essa questão da ditadura, né? Isso é história, né? Eu sei que você teve a sua passagem difícil aí nesse período, não é? Mas isso é história. 
ML - Não falo por mim, falo pela história.

AHM - A história terá que ser bem contada a esse respeito. Nós tivemos grupos organizados que tentavam implantar um outro tipo de ditadura, vamos colocar assim. Atacaram o Estado. O Estado se defendeu. E quando ocorre guerra, a primeira coisa que é vítima é a razão.

ML - O senhor tem dito, e também o candidato Bolsonaro, que o coronel Carlos Brilhante Ustra é um herói. [Mourão sacode a perna, começa a balançar os dedos da mão direita, desvia o olhar, balança a cabeça em sinal de concordância]

No período em que ele ficou no DOI-CODI, 47 pessoas morreram. Elas estavam sob a custódia do Estado. O senhor acha isso normal, que um herói deve fazer isso? Comandar um instamento militar, um local do Estado em que 47 pessoas morrem sob a custódia do Estado? [Ao final da pergunta, Mourão já voltou a olhar para a jornalista e diminuiu a agitação nas mãos]

AHM - Olha, os meus heróis não morreram de overdose, Miriam. [Sorri com ironia] Carlos Alberto Brilhante Ustra foi meu comandante quando eu era tenente em São Leopoldo. Um homem de coragem, um homem de determinação, que me ensinou muita coisa.

$M L-E$ os mortos?

AHM - Tem gente que gosta de Carlos Marighella, assassino, terrorista, autor do manual que é explorado..

ML - Eu pergunto pelo Estado, o papel do Estado brasileiro naquele momento.

AHM - Houve uma guerra, Miriam. Houve uma guerra. Excessos foram cometidos? Excessos foram cometidos. [O trecho a seguir está encoberto pela interrupção da jornalista] Houve tortura? Houve tortura.

$M L$ - Então o seu herói matou pessoas.

AHM - Heróis matam. [Desvia o olhar; silêncio de 5 segundos]

ML - Eu queria também perguntar uma coisa para o senhor sobre Reforma da Previdência...

Algumas das afirmações de Mourão sobre o que teria ocorrido no Brasil durante os governos militares - "excessos", "um homem de coragem" - e as motivações - "tentavam implantar um outro tipo de ditadura", "o Estado se defendeu", "tem gente que gosta de Carlos Marighella, assassino", "heróis matam" - são distintas das versões frequentemente citadas na mídia, nos livros de história, nas produções artísticas e, especialmente, nas universidades. Ainda assim, traduzem a perspectiva de muitos brasileiros, que não só elegeram Jair Messias Bolsonaro e Antônio Hamilton Mourão como têm deixado comentários e depoimentos de plena concordância com essas e outras declarações e versões 
sobre o passado. Nas várias postagens dessa entrevista no YouTube, por exemplo, predominam comentários elogiosos ao general e depreciativos em relação aos jornalistas.

Para o senso comum, a memória é a capacidade de guardar e descrever experiências. Vem daí a ideia de que algumas pessoas teriam "boa memória", uma capacidade inata de lembrar e compartilhar lembranças. Entre pesquisadores, costuma-se enfatizar os aspectos imaginativos e seletivos da memória, assim como sua relação com o presente:

[...] uma reconstrução psíquica e intelectual que acarreta de fato uma representação seletiva do passado (ROUSSO, 2006, p. 94).

Usualmente, a ideia de preservação do passado dá lugar à de representação:

O consenso existe igualmente em reconhecer que a memória é, acima de tudo, uma reconstrução continuamente atualizada do passado, mais do que uma reconstituição fiel do mesmo (CANDAU, 2012b, p. 9).

Mas, então, a recordação não existe e tudo é recriação?

Candau (2012b) defende a existência de diferentes facetas da memória e propõe uma classificação: a) protomemória; b) memória de alto nível; e c) metamemória. A protomemória seria a "experiência incorporada", "sem tomada de consciência", o passado que "age pelo corpo", sem que seja preciso pensá-lo e verbalizá-lo. Uma memória que tem a ver com saberes e experiências compartilhados, repetição, condicionamentos, hábitos, aprendizagens da infância, memórias gestuais. Sobre a memória de alto nível, o autor afirma:

[...] é essencialmente uma memória de recordação ou reconhecimento: evocação deliberada ou invocação involuntária de lembranças autobiográficas ou pertencentes a uma memória enciclopédica (saberes, crenças, sensações, sentimentos etc.) (CANDAU, 2012b, p. 23).

E Candau (2012b) acrescenta que dela também participa o esquecimento. Enquanto protomemória e memória de alto nível estariam diretamente ligadas a uma capacidade de memorização, no campo da metamemória é que estaríamos lidando com representações do passado: 
A metamemória, que é, por um lado, a representação que cada indivíduo faz da sua própria memória, o conhecimento que tem dela e, de outro, o que diz dela, dimensões que remetem ao "modo de afiliação de um indivíduo ao seu passado" e igualmente, como observa Michael Lamek e Paul Antze, a construção explícita da identidade. A metamemória é, portanto, uma memória reivindicada, ostensiva (CANDAU, 2012b, p. 23).

Na entrevista citada, talvez possamos afirmar que transitam pelo menos 2 tipos de memória.

Hamilton Mourão e Miriam Leitão têm a mesma idade. Ambos nasceram em 1953. Filho de um general, Mourão ingressou no Exército Brasileiro em 1972. Nesse ano, Miriam, militante do Partido Comunista do Brasil (PCdoB), grávida, foi presa e torturada por integrantes do Exército Brasileiro. Ao longo dos anos 1970, Mourão, jovem, dedicava-se à sua formação na Academia Militar das Agulhas Negras (AMAN), buscava tornar-se, como seu pai, um membro da elite militar. Miriam, na mesma época, certamente enfrentava as consequências de alguns dos episódios mais marcantes e traumáticos de sua vida, praticados justamente pelos membros da corporação na qual Mourão se esforçava para ser aceito.

Na entrevista, Mourão se refere de modo sutil à prisão e tortura de Miriam: “eu sei que você teve a sua passagem difícil aí nesse período, não é?”. A jornalista, entretanto, desvia de relacionar sua própria experiência com o tema da entrevista: "não falo por mim, falo pela história". Mourão sabe que Miriam tem uma memória de alto nível, recordações, lembranças autobiográficas sobre a violência praticada pelo governo militar. Ela, entretanto, prefere permanecer no âmbito da metamemória, de uma memória coletiva, documentada, tornada história.

[...] a expressão memória coletiva é uma representação, uma forma de metamemória, quer dizer, um enunciado que membros de um grupo vão produzir a respeito de uma memória supostamente comum a todos (CANDAU, 2012b, p. 24).

Adiante, Mourão retoma a estratégia se referindo à sua própria experiência autobiográfica, às suas lembranças como forma de validação: "Carlos Alberto Brilhante Ustra foi meu comandante quando eu era tenente em São Leopoldo. Um homem de coragem, um homem de determinação, que me ensinou muita coisa". 
Os dois interlocutores usam a palavra história.

Nesse uso, explicita-se a disputa de memórias e a busca por legitimar suas versões. A jornalista afirma: "não falo por mim, falo pela história". E o general rebate: "a história terá que ser bem contada a esse respeito". A jornalista busca questionar a afirmação de que o governo Médici teria sido melhor do que o governo Geisel, referindo-se a uma afirmação frequente de que o período Médici teria sido o mais violento, quando foi promulgado o Al-5 e intensificou-se a repressão estatal: censura, torturas e assassinatos. Já a fala de Mourão traduz uma perspectiva que, pouco debatida publicamente até então, tem ganhado força: a de que outra versão da história da ditadura militar precisa ser contada, escrita, conhecida. Uma versão certamente na qual os militares deixariam de ser vilões e assumiriam o papel de heróis.

Não à toa, no curto período da entrevista em que conversam sobre o tema, o general usa duas vezes a palavra herói.

Primeiro para questionar, com ironia, o heroísmo atribuído nas narrativas da esquerda a pessoas que atuaram politicamente com uso da violência. Ele cita Carlos Marighella, mas a lista poderia incluir ícones como Che Guevara, Fidel Castro e membros da luta armada brasileira. Em seguida, quando usa a palavra herói, ele repete o uso feito pela jornalista - que atribui a alcunha ironicamente a Ustra - como uma forma de justificar os assassinatos e as torturas, os "excessos" cometidos pelos militares.

\section{Memória e identidade}

Se a memória é um processo vivo de reconstrução do passado que ocorre no presente - envolvendo seletividade, imaginação, omissões, falseamentos, novas hierarquizações, novas narrativas, quais seriam as motivações das mudanças? Para muitos, a chave do entendimento estaria na relação indissociável entre memória e identidade. Segundo Pollak (1992, p. 204),

[...] a memória é um elemento constituinte do sentimento de identidade. 
Identidade que, lembra o autor, para a Psicologia Social e a Psicanálise, envolve: a) a sensação de ter fronteiras físicas ou de pertencimento a um grupo; b) a continuidade no tempo; e c) o sentimento de coerência. Candau (2012b) cita a recorrente relação estabelecida por diversos pesquisadores entre memória e identidade, com precedência da primeira. A memória seria responsável por construir as identidades. Para o autor, seria mais adequado pensar em indissociabilidade:

[...] não há busca identitária sem memória e, inversamente, a busca memorial é sempre acompanhada de um sentimento de identidade (CANDAU, 2012b, p. 19).

Desse modo, torna-se mais fácil entender a passionalidade nas disputas de memórias. Memórias coletivas muito distintas das minhas podem afetar e corroer meu sentimento de identidade. Assim como meu sentimento de pertencimento a um grupo afeta minha percepção da realidade e aspectos do passado que escolho ressaltar ou obscurecer.

No campo da memória, fazem parte de estratégias identitárias: a) as lembranças evocadas e não evocadas; b) os adjetivos, verbos, substantivos usados em nossas narrativas; c) os esquecimentos conscientes e inconscientes; e d) os eixos explicativos. Estratégias mais conectadas com nossos pertencimentos no presente e nossas expectativas de futuro do que com o passado. Candau (2012b, p. 33) alerta para o fato de que a

[...] parte da lembrança que é verbalizada (a evocação) não é a totalidade da lembrança.

Trata-se da parte publicizada. O momento em que lembro é distinto do momento em que os acontecimentos se deram.

Na evocação, levo em conta o que ocorreu posteriormente aos fatos, o "futuro do passado", meus engajamentos, interesses, suavizo emoções. Um fenômeno que, para Candau (2012b), explicaria os casos de "embelezamento de lembranças desagradáveis". Como a evocação faz parte da identidade que construo, é previsível que façamos escolhas que tornem a nossa narrativa autobiográfica coerente, que enfatizemos lembranças aceitáveis e silenciemos 
sobre as desagradáveis. Nossa memória trabalha em prol da imagem que queremos construir de nós mesmos.

Das falas do general Mourão, deduzimos facilmente a interpretação sobre práticas usualmente relacionadas ao período dos governos militares: abuso de poder, violações dos direitos humanos, tratamento desumano aos presos, estupros, assassinatos, censura, restrição de direitos, perseguição por motivos políticos etc. Em diversas frases, pode-se entrever os contornos de uma outra memória coletiva, na qual "grupos organizados tentavam implantar uma ditadura" e o "Estado se defendeu". Brilhante Ustra, um comandante envolvido direta ou indiretamente na tortura e no assassinato de dezenas de pessoas, torna-se "um homem de coragem, um homem de determinação". Militares cultivam uma imagem de si próprios e da corporação que combina disciplina, coragem, sacrifício, força, poder. A autoidentificação converge para o heroísmo. Mas a heteroidentificação, em muitos casos, associa a corporação e seus membros às barbáries cometidas durante o regime militar e nunca punidas.

O modo como os outros nos veem e nos definem nos afeta. Por isso, lutamos pela conquista de um olhar positivo sobre nós ou sintonizado com nossas projeções. Segundo Pollak (1992, p. 204), a identidade tem a ver com a

[...] imagem que uma pessoa adquire ao longo da vida referente a ela própria, a imagem que ela constrói e apresenta aos outros e a si própria, para acreditar na sua própria representação, mas também para ser percebida da maneira como quer ser percebida pelos outros.

Inclusive, o olhar do outro sobre nossa identidade tem nome: heteroidentificação.

Quando se refere à relação entre autoidentificação e heteroidentificação, Melucci (2004) fala em “tensão”. Isso porque a opinião do outro importa:

[...] a [autoidentificação] deve gozar de um reconhecimento intersubjetivo para poder alicerçar nossa identidade. A possibilidade de distinguir-nos dos outros deve ser reconhecida por esses "outros". [...] A construção da identidade depende do retorno de informações vindas dos outros (MELUCCI, 2004, p. 45). 


\section{Memórias coletivas}

Quando tratamos do tema memória, um autor muito referenciado é Maurice Halbwachs (1990), com sua noção de memória coletiva.

Em resumo, ele propõe que toda memória é coletiva, pois é afetada pelos nossos pertencimentos grupais. Para o autor, os "meios sociais", que constroem "quadros sociais" ou "quadros coletivos" para as nossas memórias, são fundamentais. Comentários e descrições alheias integram nossas perspectivas, tenhamos consciência ou não, pois leituras, conversas, imagens habitam nosso imaginário. Trata-se de todo um repertório de conteúdos que nos acompanha. Halbwachs (1990, p. 34) defende, ainda, que a manutenção do pertencimento assume papel relevante na manutenção da memória:

[...] para que nossa memória se auxilie com a dos outros, não basta que eles nos tragam seus depoimentos: é necessário ainda que ela não tenha cessado de concordar com suas memórias e que haja bastante pontos de contato entre uma e as outras.

Se me distancio - do grupo com o qual vivi certas experiências - isso leva ao esgarçamento da memória coletiva, pois deixaria de haver o reforço grupal. Sentimentos e ideias deixaram de ser compartilhados.

Ampliando o olhar sobre o tema da memória coletiva, autores contemporâneos têm tratado da heterogeneidade de memórias que convivem simultaneamente. Se a memória tem relação indissociável com as identidades, não seria possível esperar homogeneidade. Se são numerosos os grupos identitários em uma sociedade, o mesmo ocorre com as memórias. Candau (2012a, p. 848) diz que

[...] em toda sociedade, cada indivíduo participa de uma política da memória porque ele carrega e colore certas representações do passado do grupo ao qual ele pertence.

Ou, melhor dizendo,

[...] não se deve ocultar a extraordinária diversidade das políticas da memória para as quais cada indivíduo contribui ao longo de sua vida (CANDAU, 2012a, p. 848).

O ponto fundamental é o de que são muitas as memórias em circulação a respeito dos mesmos temas: 
[...] é por causa dessa marca individual no "fluxo memorial" que nunca há, propriamente dizendo, construção de uma memória coletiva, mas de várias (SHAHZAD, 2011 apud CANDAU, 2012a, p. 848).

Memórias que, inclusive, podem ser antagônicas.

E assim começam as disputas, tanto no campo da memória de alto nível quanto da metamemória. Se a memória evocada publicamente por outros é muito distinta das que são evocadas por mim e pelos grupos aos quais eu me filio, tensões são inevitáveis:

David Thelen nos lembra que "como as memórias das pessoas conferem segurança, autoridade, legitimidade e, por fim, identidade ao presente", não é de surpreender que "os conflitos acerca da posse e da interpretação das memórias sejam profundos, frequentes e ásperos" (THOMSON; FRISCH; HAMILTON, 2006, p. 85).

Ao participar de um grupo, pelos relatos eu aprendo o que merece ser lembrado ou esquecido, quais são as palavras adequadas para descrever as experiências, quais são os caminhos narrativos para interpretá-las. Candau (2012b), citando Maurice Bloch, afirma que não se pode confundir a narrativa de um acontecimento, a parte verbalizada, com a totalidade da lembrança. Ainda assim, a metamemória, o discurso dito, escrito, socialmente compartilhado sobre o passado tem efeito sobre cada um de nós:

[...] esse discurso pode ter efeitos performativos sobre essa memória, pois, retomado por outros membros, esse discurso pode reuni-los em um sentimento de que a memória coletiva existe (CANDAU, 2012b, p. 34).

Frases ditas pelo general Mourão à jornalista Miriam Leitão foram apenas vestígios de um iceberg muito maior e ignorado por inúmeros brasileiros: a peculiar memória que circula nas Forças Armadas a respeito do regime militar. Ao longo da campanha eleitoral, parte dessa memória veio à tona de várias formas: em falas do candidato Bolsonaro e seus filhos, em declarações de seus apoiadores, em argumentos dos seus eleitores. Mas a síntese mais clara foi divulgada no final de março de 2019, quando, poucos dias antes de completaremse 55 anos do golpe, o Ministério da Defesa divulgou a "Ordem do Dia Alusiva ao 31 de Março de 1964" (AZEVEDO E SILVA et al., 2019). Nesse texto, ficamos 
sabendo que as Forças Armadas sempre estiveram alinhadas com as "legítimas aspirações" da gente brasileira e interromperam a "escalada em direção ao totalitarismo", assumindo o "papel de estabilização daquele processo". Que observar o Brasil daquela época sob uma perspectiva histórica nos permitirá "constatar a verdade". Para os que ainda duvidavam do desejo, dentro da corporação, de restaurar sua imagem, não resta mais dúvida.

Mesmo como neófitos, podemos supor que há uma memória forte ou organizadora sobre o tema nas Forças Armadas. Na acepção de Candau (2012b, p. 44), memória forte é aquela

[...] massiva, coerente, compacta e profunda, que se impõe a uma grande maioria dos membros.

Em grupos extensos, ele prefere falar em "memória organizadora". Reforçar tal memória se mostra importante para a coesão grupal:

[...] a irrupção da possibilidade da dúvida no grupo fragilizará ou mesmo arruinará uma retórica holista (CANDAU, 2012b, p. 41).

É fácil deduzir, portanto, que em diversos momentos, no interior desse grupo, vinha sendo reforçada uma memória própria do regime militar, divergente em vários aspectos das memórias dos perseguidos pelo regime, das versões que circulam nas universidades, nos livros, que embasaram tantos filmes. Uma memória que agora emerge e aparece publicamente.

Se Mourão faz afirmações sobre o período militar em sintonia com a narrativa que o Ministério da Defesa publicou em seu site e que foi lida em todos os quartéis da Marinha, do Exército e da Aeronáutica, não à toa, Miriam Leitão evita situar-se, durante a entrevista, como participante dos fatos. Sua perspectiva é muito distinta da que ela tinha quando foi presa e torturada. Ela não é mais membro do mesmo grupo, não é mais militante do PCdoB. Está ali devido à sua experiência profissional, pois se trata de uma jornalista renomada. A citação das experiências que a jornalista viveu no período, de modo condescendente - "eu sei que você teve a sua passagem difícil aí nesse período, não é?” - também é uma forma de indicar o quadro social do qual partiriam as perguntas da jornalista. Um procedimento incomum em entrevistas. Seria mero acaso, uma gentileza ou um modo sutil de deslegitimar o(a) entrevistador(a)? 


\section{Memórias fechadas e abertas}

A memória verbalizada por um grupo não se confunde com as lembranças de cada um de seus membros. O pertencimento a um grupo não nos esgota e são muitos os grupos aos quais pertencemos, simultaneamente. Entretanto, não se deve desprezar a importância das memórias que contribuímos para reforçar. Entre os elementos constitutivos da memória, Pollak (1992, p. 201) situa os acontecimentos vividos por nós mesmos e os "vividos por tabela", experimentados "pelo grupo ou pela coletividade à qual a pessoa se sente pertencer. [...] podemos falar numa memória quase que herdada”. De modo que, muitas vezes, já não sabemos se vivemos algo ou ouvimos falar.

A dúvida e a complexidade, nesses casos, não são bem-vindas. Memórias fortes, organizadoras, criam explicações do mundo e versões dos fatos que não aceitam refutações. Em sua entrevista, Mourão até usa, de passagem, a palavra tortura. Em sua visão, uma consequência da "guerra" que os militares foram obrigados a travar. Mas não foram poucas as manifestações de absoluta incredulidade, no mesmo período, diante do depoimento de Maria Amélia de Almeida Teles, conhecida como Amelinha, em um dos programas do candidato Fernando Haddad. Militante de esquerda na época da ditadura, ela descreveu com detalhes as torturas que sofreu sob comando, justamente, do "herói” Ustra. Deslegitimar a memória oral das vítimas, como se sabe, é um procedimento antigo, assim como o negacionismo. Amelinha passou a ser vítima de uma intensa campanha de difamação nas redes sociais, promovida por eleitores de Bolsonaro que a ameaçavam, atribuíam-lhe falsos crimes e negaram que tivesse sido torturada. Em 2008, a própria Justiça brasileira reconheceu o envolvimento do coronel Ustra nessa e em outras torturas - e reafirmou sua decisão em 2012.

Nosso interesse não é verificar qual lado conta a verdade, mas observar a diversidade de memórias que circulam e quais seriam os benefícios e os riscos. A existência de diferentes memórias é natural, pois enxergamos os acontecimentos sob óticas distintas, e isso pode amenizar as generalizações que simplificam o que é complexo. Nem todo alemão que participou do Exército Nazista odiava os judeus ou amava Adolf Hitler. Muitos eram apenas cidadãos coagidos, obrigados a se alistar. Nem todos os militantes de esquerda que lutaram contra a ditadura militar no Brasil tiveram apenas atitudes nobres e 
heroicas ${ }^{1}$. Assim como nem todos os militares brasileiros compactuaram com os horrores da ditadura. Os descontentes foram perseguidos, exonerados e também foram vítimas, eles próprios e suas famílias, de torturas e assassinatos (COMISSÃO DA VERDADE DO ESTADO DE SÃO PAULO, 2020).

Podemos escolher o caminho das memórias fechadas ou das memórias abertas,

[...] escolher uma memória "fechada", exclusiva de tudo o que não é ela, ou "aberta", inclusiva das memórias alternativas (CANDAU, 2012a, p. 848).

Memórias abertas reconhecem a existência de outras versões das mesmas experiências. Memórias fechadas defendem a própria versão da memória coletiva como a única possível. A escolha tem grande significado. Memórias abertas são inclusivas, memórias fechadas são excludentes. Como vivemos em sociedades heterogêneas, escolhemos entre

[...] um "nós" exclusivo e um "nós" inclusivo (CANDAU, 2012a, p. 849).

O desafio é encontrar o ponto justo, pois, alerta Candau, políticas da memória

[...] caracterizadas por um fechamento grande demais - sob forma de contrações memoriais e identitárias - podem proibir qualquer reconciliação, ao passo que uma abertura grande demais pode fazer o jogo daqueles que têm interesse em mascarar seus crimes (ROBBEN, 2012 apud CANDAU, 2012a, p. 849).

Um aspecto que não pode ser esquecido é o risco de falsificação de memórias. Governos repressores usam com abundância o recurso de criar inimigos ou fantasiar sobre eles, estimulando exageros e antagonismos (CANDAU, 2012a). Na entrevista do general Mourão, encontramos vestígios de concepções que passaram a ser mais bem conhecidas após as eleições em declarações do presidente, de seus filhos e de seus ministros, como: a) a eleição de Bolsonaro seria a chance de livrar o Brasil do socialismo; b) vivemos sob domínio do marxismo cultural; c) vivemos sob ataque do globalismo; d) durante o regime 
militar, perseguições e torturas ocorreram como exceção; e e) a execução de militantes foi cometida mais frequentemente por seus próprios companheiros. Se na narrativa sobre o passado, que aparece na Ordem do Dia lida nos quartéis, comunismo e nazifascismo eram as principais ameaças à liberdade e à democracia, no Brasil de 2019 estaríamos sob ameaça de inimigos similares.

A falsificação da memória serve a uma estratégia de esquecimento. O esquecimento é parte da memória. Somos incapazes de recordar tudo o que vivemos. E também é uma estratégia de sobrevivência para lidar com acontecimentos traumáticos. Esse esquecimento não se confunde com a estratégia de negar acontecimentos ou distorcê-los intencionalmente. Nesse segundo caso, trata-se de um esquecimento consciente,

[...] voluntário porque, pelo contrário, ele cria ou mantém oposições (CANDAU, 2012a, p. 861).

Se, na entrevista, a declaração do general foi expressiva, mas vaga - "a história terá que ser bem contada a esse respeito" -, após a vitória, outros foram mais explícitos (FOLHA DE S.PAULO, 2019).

Vivemos, no Brasil de 2019, uma clara disputa de memórias. Caminhar para memórias fechadas, como está sendo proposto, não nos ajudará a lidar com o nosso passado nem a construir diálogos necessários entre grupos tão distintos. O que pode ser não uma solução, mas uma trilha em direção menos acidentada, é insistir na abertura das memórias, no reconhecimento de que outras memórias existem, são possíveis e merecem nossa escuta. Mitificar e blindar os aliados e demonizar os opositores é a estratégia das memórias fechadas - em muitos momentos usada no Brasil tanto pelos movimentos de direita quanto pelos de esquerda.

A memória partilhada socialmente não é a totalidade da lembrança de cada um. Existe, sim, um caldeirão de lembranças com outros ingredientes, ainda que encobertos. Tão saudável quanto lidar com as memórias dos perseguidos talvez seja lidar com as memórias dos perseguidores. Ampliar a escuta para outros tipos de vítimas, como os militares que não aceitaram ir contra a democracia. Saber mais sobre os militantes que perseguiram e até mataram os 
próprios companheiros. Quando falamos de memórias, também falamos das identidades, dos afetos, da autoestima. Não é possível insistir que o outro se despoje de suas máscaras se eu não me despojo das minhas ou exigir que o outro reconheça seus erros se eu não reconheço os meus. Para estabelecer uma ponte entre Brasis que não dialogam e enfrentar a tentativa de fechamento das memórias, parece urgente a aceitação de que heroísmo e vilania não escolhem lado. Tenhamos a formação ou a adesão política que for, somos todos complexos e contraditórios. Uma abertura de memórias que não se confunde com minimizar ou perdoar crimes, mas que acredita na ampliação da escuta como modo de fortalecer democracias.

\section{Referência}

AZEVEDO E SILVA, Fernando et al. Ordem do Dia Alusiva ao 31 de Março de 1964. 27 mar. 2019. Disponível em: <https://www.defesa.gov.br/noticias/54245ordem-do-dia-alusiva-ao-31-de-marco-de-1964>. Acesso em: 20 abr. 2019.

CANDAU, Joël. A memória e o princípio de perda. Diálogos, Maringá, v. 16, n. 3, p. 843-872, 2012a.

CANDAU, Joël. Memória e identidade. São Paulo: Contexto, 2012b.

COMISSÃO DA VERDADE DO ESTADO DE SÃO PAULO. A perseguição aos militares que resistiram à ditadura. Disponível em: http://comissaodaverdade.al.sp.gov.br/relatorio/tomoi/downloads/I_Tomo_Parte_1_A-perseguicao-aos-militares-que-resistiram-aditadura.pdf. Acesso em: 14 abr. 2020.

FERRAZ, Lucas. O lado 'dark' da resistência: a luta armada e o justiçamento de militantes na ditadura. 17 jun. 2012. Disponível em: https://www1.folha.uol.com.br/fsp/ilustrissima/49213-o-lado-dark-daresistencia.shtml. Acesso em: 14 abr. 2020.

FOLHA DE S.PAULO. Ministro diz que não houve golpe em 1964 e que livros didáticos vão mudar. 3 abr. 2019. Disponível em: https://www1.folha.uol.com.br/educacao/2019/04/livros-didaticos-vao-negargolpe-militar-e-ditadura-diz-ministro-da-educacao.shtml. Acesso em: 14 abr. 2020. 
GLOBONEWS. Central das Eleições recebe general Mourão, candidato a vice na chapa de Jair Bolsonaro. Com a participação de Heraldo Pereira, Fernando Gabeira, Merval Pereira, Cristiana Lôbo, Andréia Sadi, Miriam Leitão e Gerson Camarotti. 7 set. 2018. Disponível em:

https://globosatplay.globo.com/globonews/v/7004935/. Acesso em: 14 abr. 2020.

HALBWACHS, Maurice. A memória coletiva. São Paulo: Vértice, 1990.

MATHEUS, Letícia Cantarela. Comunicação, tempo, história: tecendo o cotidiano em fios jornalísticos. Rio de Janeiro: Mauad X Faperj, 2011

MELUCCI, Alberto. O jogo do eu: a mudança de si em uma sociedade global. São Leopoldo, RS: Ed. Unisinos, 2004.

POLLAK, Michael. Memória e identidade social. Estudos Históricos, Rio de Janeiro, v. 5, n. 10, p. 200-212, 1992.

ROUSSO, Henry. A memória não é mais o que era. In: FERREIRA, Marieta de Moraes; AMADO, Janaína (org.). Usos \& abusos da história oral. Rio de Janeiro: Ed. FGV, 2006. p. 93-101.

THOMSON, Alistair; FRISCH, Michael; HAMILTON, Paula. Os debates sobre memória e história: alguns aspectos internacionais. In: FERREIRA, Marieta de Moraes; AMADO, Janaína (org.). Usos \& abusos da história oral. Rio de Janeiro: Ed. FGV, 2006. p. 65-91. 